\title{
Experimentation and simulation process of friction stir welding for lightweight similar and dissimilar materials
}

\author{
Variavel. $\mathrm{M}^{1}$, Pugazhenthi. $\mathrm{R}^{2 *}$, Jayakumar. $\mathrm{V}^{3}$ \\ ${ }^{1}$ Research Scholar, Department of Mechanical Engineering, VISTAS, Chennai, Tamilnadu, India. \\ ${ }^{2}$ Department of Mechanical Engineering, VISTAS, Chennai, Tamilnadu, India. \\ ${ }^{3}$ Department of Mechanical Engineering, Saveetha School of Engineering, Saveetha Institute of Medical and Technical Sciences, \\ Chennai, Tamilnadu, India.
}

\begin{abstract}
The emerging trends in advanced robust manufacturing trend need light and medium weight materials with higher strength for different purposes. The aluminum and copper alloys are the major construction material for different causes in aerospace, railway and shipbuilding industries. Joining of dissimilar material during built-up structures is one of the tough tasks of the manufacturer; joining of similar and dissimilar material can be effectively made in the Friction Stir Welding (FSW). In this research article made an attempt to find an optimal process parameter for lap joining process in FSW for Al 5052, Al 6061 joining with copper. The finite element simulation model of the lap joint designed, analyzed and simulated with consideration of various spindle speed of $\mathrm{CNC}$ machine, an optimal speed condition found and which is applied in during the manufacturing. The fabricated workpieces were tested and the results were compared with the simulated model result, it shows that the fabricated dissimilar materials workpieces are superior to the simulated results especially in tensile load conditions.
\end{abstract}

\section{Introduction}

Automotive vehicle controls and performance analysis purely is focused on economics and minimized mass weight comp activeness issues in further applications of the different light motive vehicle body and minimize the vehicle weight analysis is performed. Advanced magnesium in the robust surfaced areas will be presented in values assignment in $2.5 \%$ to $5 \%$ in the number of finite elements. Most of it represents in this element are examined in magnesium alloyed in highest specific strength analyses in steels and alloys [1].

In this the aluminum alloy its feasible joining process is determined in different bonding as well as mechanical fastening and the welding process wherever to in TIG, MIG welded in this method are employed deformation results as studied in the different cast of problems. This research is differentiated to the practical in hand lay-up blind, welding process in FSW systems explored applied in pre-drill holes. In this result outcome is applied in different join dissimilar joint casts Mg Alloy - Am60 and $\mathrm{Al}$ Alloy Sheets with four joints of groupings play AA6082-AM60, AM60-AA6082 joints. The special study of this process window of the high quality of the joint process causes to design with strengthening and non-quality issued in the different working process of systems [2]. The scenario of operation parameters induced in joint strength as measured in lap -shear tensile effects on different instruments observed various techniques and analyses [3]. The process of figures is determined by simulating the boundary function and process with parameters as shown in figure 1.1. This is examined in a tail forming process of this paper while conventionally analysis in the blind, welding system can be simulated in FSW removes as diverse miss the tail forming process in peril hole method.

In this working dissimilar joint are classified AA6082AM60, AM60-AA6082, and AM60-AA6022. This study is focused to explored in different systems should be carried in maximum quality monitored and discussed it pre-determined functions having the process of systems is presented in this parameters affects the joints applied in different discussing of systems in joint strength in lap shear analyses in tensile and compressive experimentation system analyses in observed phenomena of this results [4]. To examine this rotating friction drilling process in dissimilar in $\mathrm{MG}$ alloys to development in varies engineers concluded in problems functions in high shrinkage and large fusion zone affected zones and significant effects and maximize the residual effects and disable properties effects and fewer durability effects [5], [6]. The similar problems considering large fusion and exploring assembly effects and stress induced in blind welding properties assigning in adhesive process of related hybrid joining process [7]. This research FSW held on fixture systems are examining in robust speed $(\omega)$ and feed rate simulated in $(f)$ distinguish it. Wherever, this residual stress, however, presented this significance of predefined penetration forces will be shank effectiveness are misshapen in this long-drawn-out in mandrel head into the shank. Moreover this material significant 
conventional or robust fusion generating process [8]. The most of problem causes find in aluminum and steel which impact in the automotive industry in different examine of this process like thermal permeability and conductivity and diffusivity and electrical coefficient of this process in Fe-Al binary of this calibre. The aim of phase flow techniques have been used it [9]. This recently of this process determined in Flow in pre-drill [FPD] is alternative kinds of joining process can be presented in screw inserted torque effectiveness forces to forms full engagement effects in this materials are examined it. This typically pre-drills systems adhesively propagated in FPD process more tensile and compressive behaviour performance of the load affected in thermal fusion behavioural it [10]. Most of the scientific researchers define in FPD process popular in marine and aeronautical industry low conductivity of less impact load to be designing chip free system analysis in deformation of this process [11]. Solid welding is an important metal joining process in which a hole made in the sheets and then the rivets were used to join the sheets. A self-piercing welding is introduced to improve the process of the sheets. Both these processes require the two-side access, which may be difficult and significantly slow down the joining process. A new metal joining process called Friction stir blind welding (FSW) is developed by [12]. This process involves a combination of friction stir welding and blind welding. The FSW process eliminates the need for the separate hole-making operation required in the conventional blind welding process while retaining the advantage of onesided accessibility conducted [13]. The experiments are carried out on 3 mm-thick AA 5052 sheets using FSW joints and clearly found that the joints withstand a larger tensile load and possess a high fatigue resistance compared to electrical resistance spot welded joints [14]. They are joined a dissimilar high strength steel DP600 $(1 \mathrm{~mm})$ and magnesium alloys AZ31B $(3 \mathrm{~mm})$ sheets using FSW process [15]. The riveted joints in die-cast and wrought Al alloys as well as Mg AZ31 sheet using FSW process with several types of blind rivets. They concluded that rivets with a hollow mandrel head capture the workpiece material displaced by the river within the mandrel head cavity and require lower penetration forces. FSW process employed for joining the Mg AZ31 and DP600 steel sheets [16]. CFRP and aluminum alloy sheets joined by using FSW process. Three combinations of material stack-ups in a lap shear joint configuration such as CFRP-CFRP, CFRP-AA6111, and AA6111CFRP are fabricated. Joints made between AA6111-T4 $(0.9 \mathrm{~mm})$ and AA6022-T4 $(2.0 \mathrm{~mm})$ by using FSW process with spindle speeds of 1750 and $2750 \mathrm{rpm}$ and various feed rates [16]. Tensile tests are carried out to investigate the mechanical properties of the joints explained the mechanics in the FSW process when joining similar and dissimilar Al alloy sheets. Further, the process window broadened by the optimization of rivet and FSW process and thereby increases its industrial relevance. Recently, explored failure modes in FSW lap shear joining of dissimilar materials ( $\mathrm{Al}, \mathrm{Mg}$, Carbon fiber reinforced polymeric composite) achieved the marine atmospheric corrosion behaviour of $\mathrm{Al}-\mathrm{Mg}$ joints at severe marine test surroundings.

As reviewed above, only a very few research papers discussed the joining of dissimilar materials using FSW process. The dissimilar alloys sheets increasing and employed with the alternative materials in the aircraft and automobiles to reduce the weight and to enhance the performance. However, the high cost of alloys, the different combination dissimilar of alloy sheets are likely to be tested in the aircraft and trucks. Therefore, the dissimilar joining of alloys sheets is a key enabling technology for wider adoption of lightweight bodies in aircraft and automobile applications. Hence, the joining of dissimilar alloys using FSW process with different combination need to be studied. This research deals with the FSW of similar and dissimilar metals of copper sheets and aluminum alloy sheets. The copper and its alloys are the most important materials in engineering application, because of their good corrosion resistance, outstanding electrical and thermal conductivity, attractive appearance, good strength, ductility and ease of fabrication. The aluminum alloy sheets are known for their greater ductility and larger thermal conductivity. In this research article, the different combination of similar and dissimilar joints of $\mathrm{Cu}-\mathrm{Cu}, \mathrm{Al} 5052-\mathrm{Al} 5052, \mathrm{Cu}-$ $\mathrm{Al}$ 5052, $\mathrm{Al}$ 6061- $\mathrm{Al}$ 6061, Cu - Al 606 (1.5 mm) are fabricated using the FSW process with spindle speeds of 1110,1750 and $2750 \mathrm{rpm}$. In FSW process, first alloy sheet is placed on the top side and second alloy sheet is placed on the bottom side. The tensile tests are conducted to determine the mechanical properties of the joints and the microstructure of the interface has been studied to understand the behavior.

\section{Workflow and consideration}

These robust presentation new joining methods, which examine and excite the automotive industry, helping of the pre-drill rivet insertion system inspected in simulation analysis of this FSW process. The first process generative a modeling in mechanical joining process significantly in classified in the different type of materials in examining it. This process will prove in lap shear effects will define it. This process of similar and dissimilar materials in considering the thermal characterization of this property and diffused and observed in bounty condition in single lay-up methods and techniques followed in ANSYS workbench. This function of the main monitoring system is the combinations and spindle speeds and it examines indifferent during of deformation effecting on the sheer force with respect to stress induced in lateral strain in the $\mathrm{x}$-axis.

\section{Standard of FEA}

The present computation techniques used to obtain in minimized in uncontained solution are exploring these undefined problems examine in engineering. This study of boundary value problems is mathematical problems in which one or dual different unknown variables 
specifically defined in the differential equation where defined in different domains. In this FEA analysis unsophisticated in the description of Finite methods involves in equations and nodes involves in present shear force structure in automotive industries.

\subsection{Generative modeling}

This ignition of finite element analysis in considering in concepts of design structure can be simulated by the mechanical behavior of this characterization this ASTM standard follows in prepared in three-dimensional model preparation in this simulated in this without behavior analysis of modeled it. The Finite element considers in IGES file programs represented in nodes and elements. This modeled induced behavior of different lateral and examine the original shear force on this similar and dissimilar materials obtained in this generative designed of this modeling it. The helping of this robust design in solid works examined in present papers in the different shear force in different shapes and application. In this system are examined in the steams of the endpoint to radius effectiveness and models pre-determined solutions are presented in dimensions as shown in figure 1.

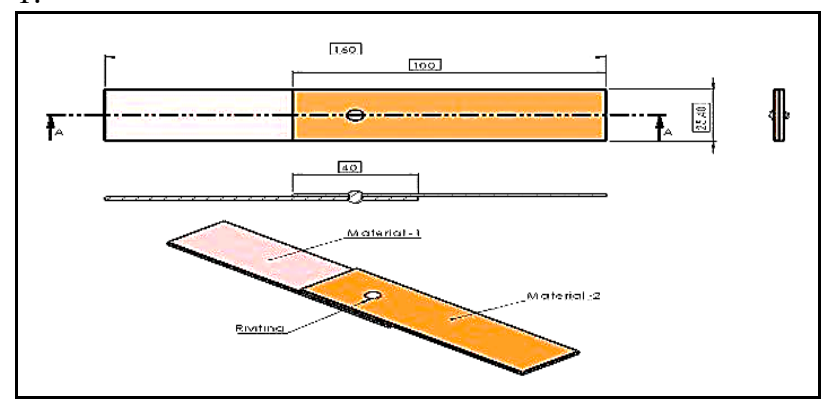

Fig. 1. Geometry model in the workpiece

The size of the test pieces of aluminum alloy and copper sheets are $6 \mathrm{~mm} \times 100 \mathrm{~mm}$, along with the lengthwise and transverse directions respectively.

Table 1. Common mechanical properties

\begin{tabular}{|c|c|c|c|}
\hline $\begin{array}{c}\text { Material } \\
\text { parameters }\end{array}$ & AI5052 & AI6061 & Copper \\
\hline $\begin{array}{l}\text { Modulus of } \\
\text { Elasticity, E (MPa) }\end{array}$ & 71,300 & 67,900 & 79500 \\
\hline Poisson ratio, v & 0.33 & 0.33 & 0.27 \\
\hline $\begin{array}{c}\text { Mass density, q } \\
\text { (Mg/mm3) }\end{array}$ & $2.18 \mathrm{E}^{-09}$ & $\begin{array}{c}2.60 \mathrm{E}^{-} \\
09\end{array}$ & $8.15 \mathrm{E}^{-09}$ \\
\hline $\begin{array}{c}\text { Yield strength, r0 } \\
(\mathrm{MPa})\end{array}$ & 88.6 & 54.2 & 41.1 \\
\hline
\end{tabular}

The thickness of both sheets is $15 \mathrm{~mm}$. For rivet insertion, one coupon placed on top of the other with a $50 \mathrm{~mm}$ overlap as shown in Figure $2 /$ Table 1 Mechanical Properties.

\subsection{Boundary conditions}

The most of the researchers, the usual analysis in ANSYS is consumed domestic mechanical behavior analysis of technology functions determined in algebraic calculations and determined in significant threedimensional cross-sectional areas effects in these two nodes 3 elements triangular element function assigned in this instance of these systems obtained it. This respective of deformation effects are discussed in theoretical solution and shear deformed in engineering governed concern this loads and predetermined load positions and joint equations functionally and probable solution of this method and structures it. This theoretical solution is examined in stress distribution affection more effectiveness and without discontinuity error, less system is simulated it.

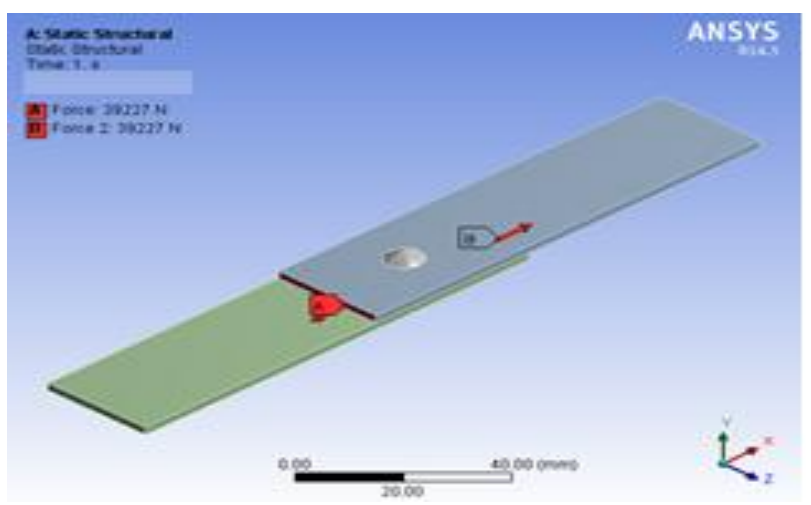

Fig. 2. Boundary conditions



Fig. 3. Meshing FSW model

This main issue while examining in effectively and manifested a problem defines inefficient problems are considered in this structured is performed it.in this order to determine in FEA procedure a is first manual presenting is assured that in this structure of works. The numerical solution is mainly determined betterment solution is spatial shear deformation solution analysis in different variables of this system. These systems are examined in analytically and systematically analysis in a compact sized of visualized structures in connecting nodes and free elements are distinguished in this mesh or defragmentation mode of the spiritual equation of this solved in unknown solution effects is designed it. The 
computational solution effects are the prediction of the intended solutions and results of finitely presented and successful it.

\section{Materials selection / characterization}

The betterment and reinforcement and provide and high rigidity and share load constrains joint to the axis to vector instead of having pure lateral deformation effects in this importance of properties in density and modulus of elasticity, Poisson ratio and yield stretch wherever reinforcement shims. The most of a wide range of aluminum and copper alloyed materials its simple shear deformation states of schematization aspects chemical composition and combination as given in this Table 2, 3

Table 2. Chemical compositions

\begin{tabular}{|c|l|}
\hline Material & \multicolumn{1}{|c|}{ Chemical composition } \\
\hline \multirow{2}{*}{$\mathrm{Al} 5052$} & $\begin{array}{l}\mathrm{Mg}-2.7 \%, \mathrm{Cr}-0.25 \%, \mathrm{Cu}-0.2 \%, \mathrm{Fe}-0.3 \%, \mathrm{Mn}- \\
0.2 \%, \mathrm{Si}-0.27 \%, \mathrm{Zn}-0.2 \%, \mathrm{Al}-97 \%\end{array}$ \\
\hline \multirow{2}{*}{$\mathrm{Al} 6061$} & $\begin{array}{l}\mathrm{Mg}-1.3 \%, \mathrm{Cr}-0.38 \%, \mathrm{Cu}-0.5 \%, \mathrm{Fe}-0.8 \%, \mathrm{Mn}- \\
0.17 \%, \mathrm{Si}-0.9 \%, \mathrm{Zn}-0.27 \%, \mathrm{Al}-97.2 \%\end{array}$ \\
\hline \multirow{3}{*}{ Copper } & $\begin{array}{l}\mathrm{Fe}-0.002 \%, \mathrm{Zn}-0.0002 \%, \mathrm{Cu}-98.99 \%, \mathrm{~Pb}- \\
0.004 \%, \mathrm{Ag}-0.0026 \%, \mathrm{As}-0.0015 \%, \quad \mathrm{O}-\end{array}$ \\
& $0.0015 \%, \mathrm{Sb}-0.0014 \%, \mathrm{Te}-0.0012 \%$ \\
\hline
\end{tabular}

Table 3. Combinations of Diffèrent Joints

\begin{tabular}{|l|l|l|l|l|l|}
\hline \multirow{2}{*}{$\begin{array}{c}\text { Position of } \\
\text { sheet metal }\end{array}$} & \multicolumn{5}{|c|}{ Combinations } \\
\cline { 2 - 6 } & $\mathbf{1}$ & $\mathbf{2}$ & $\mathbf{3}$ & $\mathbf{4}$ & $\mathbf{5}$ \\
\hline Top Metal & $\begin{array}{l}\mathrm{Al} \\
5052\end{array}$ & $\begin{array}{l}\mathrm{Al} \\
6061\end{array}$ & $\mathrm{Cu}$ & $\begin{array}{l}\mathrm{Al} \\
6061\end{array}$ & $\begin{array}{l}\mathrm{Al} \\
5052\end{array}$ \\
\hline Bottom Metal & $\begin{array}{l}\mathrm{Al} \\
5052\end{array}$ & $\begin{array}{l}\mathrm{Al} \\
6061\end{array}$ & $\mathrm{Cu}$ & $\mathrm{Cu}$ & $\mathrm{Cu}$ \\
\hline
\end{tabular}

\section{Experimental presentation}

The experimental methods follow in The two coupons are clamped to the workpiece fixture. The coupon surface is perpendicular to the direction of the rivet insertion and the rivet insertion point should be at the center of the overlapped section, i.e., mid width and mid-length. A commercially available Aluminum 5052 rivet with a shank diameter of $4 \mathrm{~mm}$ is used in for conducting the tests. A specially made workpiece fixture of mild steel plate is used to avoid the slippage of the workpiece during the welding process.

\subsection{Shear load analysis}

The simulation and experimentation effects of analysis in tensile tests were carried out on a 40-Ton universal Instron 5582 testing machine at a crosshead speed of $5 \mathrm{~mm} / \mathrm{min}$ with a room temperature. The spacers used in the tensile tests to keep the joint parallel to the tensile axis, which will prevent the binding. The gripping area on both ends is $25.4 \times 25.4 \mathrm{~mm}^{2}$ is similar functions inspected in the different revelation of this result.

\subsection{Simulation analysis of riveted joints}

The Nominal extreme values of Von-misses stress in FSW joint is $443.66 \mathrm{~N} / \mathrm{mm}^{2}$ and the minimized values of attending stress induced it where the number of values described in this $0.06 \mathrm{~N} / \mathrm{mm}^{2}$. The FSW was Decartelization by using Tet and Mapped mesh as Follows. The hybrid alloyed riveted Design and development meshed in varying classifications used in the hexagonal element. The minimum Value of the shear Stress in Alloyed material reminders shown values present my Directional $156.82 \mathrm{~N} / \mathrm{mm} 2$ it was adopted techniques utilized in this Laminates. The maximum values presented of the shear stress in Alloyed Compositions 6061-Cu found to be higher stress induced to compare to other. This located around the FSRB is constructed simulation analysis result of Von-misses Stress and Shear strain of similar composition riveted joints are shown in this table and figure 4. This respective of Vonmisses stress in force, shear stress induced iteration in this Simulation process to describe in this dissimilar material riveted joints is shown in figure 5 .

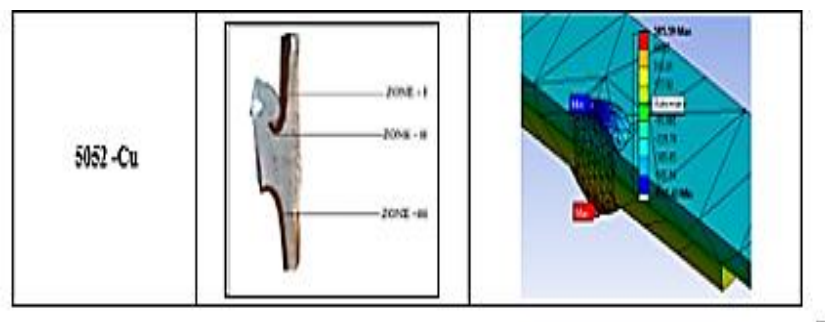

Fig. 4(a). Dissimilar joints 5052-Cu Composition FSW processor

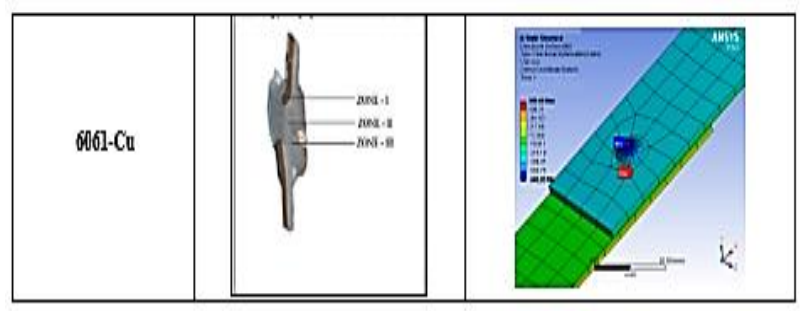

Fig. 4(b). Dissimilar joints 6061-Cu Composition FSW processor 


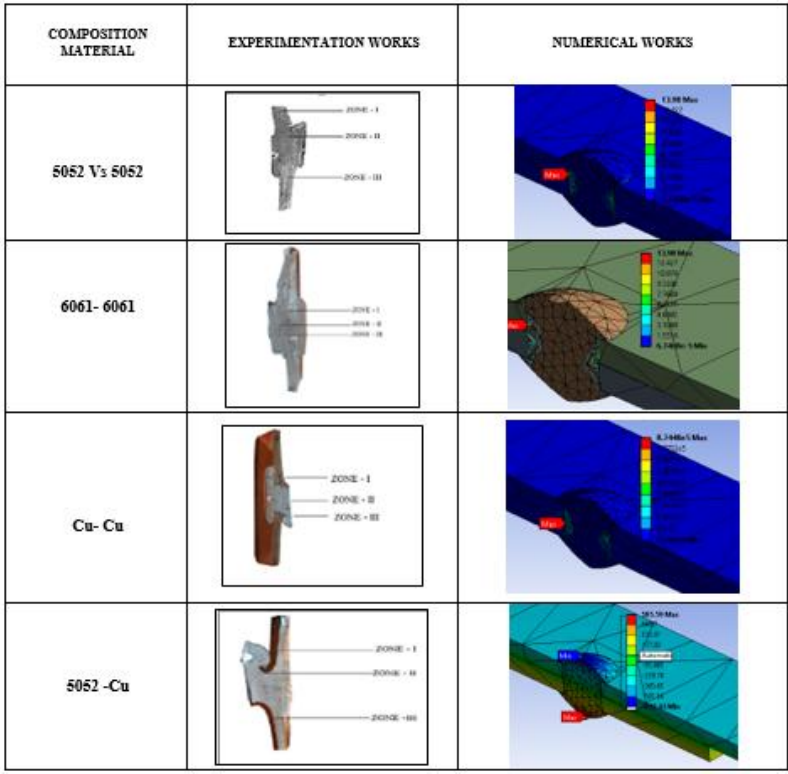

Fig. 5. Smaller material joints FSW processor

\section{Results and discussion}

\subsection{Experimentation results}

The effects of the similar and dissimilar FSW process parameters upon the lap-shear strength and the results obtained from the tensile test result were compared with the different combinations. The figure shows the ultimate tensile strength of the joints for various material combinations with different spindle speeds. In similar joints, Al 5052 - Al 5052 and Al 6061- Al 6061 combinations showed better results except for $\mathrm{Cu}-\mathrm{Cu}$. Due to insufficient bonding, $\mathrm{Cu}-\mathrm{Cu}$., exhibits the poor result. In the case of dissimilar metals, the Al 6061- $\mathrm{Cu}$ joint exhibited better strength compared to its counterpart $\mathrm{Al} \mathrm{5052-} \mathrm{Cu}$. This is due to the reason that the rivet penetrates the $\mathrm{Al} 6061-\mathrm{Cu}$ sheet and merges with the parent metal completely when compared the other combinations.

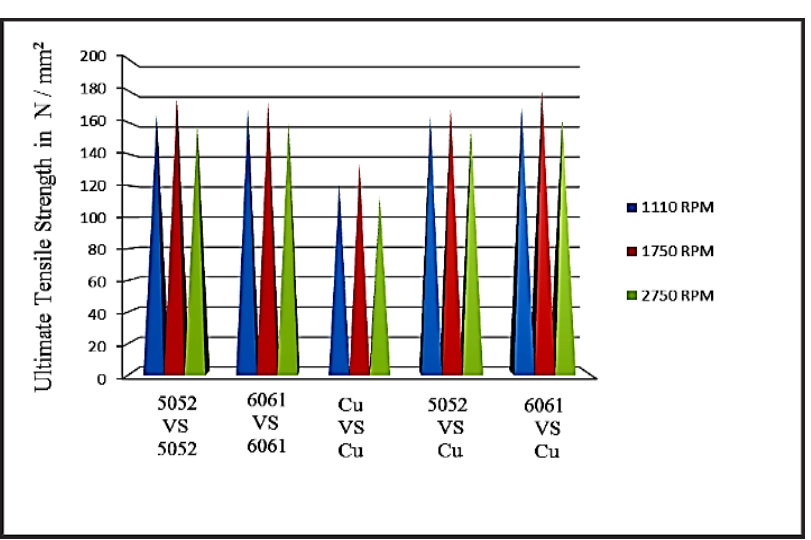

Fig. 6. The ultimate tensile strength of the joints for various material combinations

Comparison of the ultimate tensile strength of different material combinations with different spindle speeds.

\subsection{Simulation results}

This five combinations of material schematization of alloyed materials in without shear failure shims used in uncertain structure failure assignment of solid theory effects. The hyper-explicit dynamic modelling analysis is most of the suitable modelling and flexible shear in defending level of different unpredicted ions from different models having in this model and founded by suitable for present ASTM models having very closely matched in the test data of works fitted value assignment to deliver Table 4 Composition of material Vs simulation parameters in within $12-16 \%$ responsibility of experimental data is examined it. The finite element analysis of flex seal using evaluated and materials models in detail in this graph shown in Figure 6.

Table 4. Composition of material Vs simulation parameters

\begin{tabular}{|c|c|c|c|}
\hline $\begin{array}{c}\text { Composition } \\
\text { of material }\end{array}$ & $\begin{array}{c}\text { Von misses } \\
\text { Stress } \\
\mathbf{N} / \mathbf{m m}^{2}\end{array}$ & $\begin{array}{c}\text { Von } \\
\text { misses } \\
\text { Strain }\end{array}$ & $\begin{array}{c}\text { Deformation } \\
\text { in mm }\end{array}$ \\
\hline \multicolumn{4}{|c|}{ Similar material } \\
\hline $5052-5052$ & 1561.1 & 2.212 & 0.261 \\
\hline $6061-6061$ & 1643.4 & 2.641 & 0.341 \\
\hline $\mathrm{Cu}-\mathrm{Cu}$ & 1411.1 & 1.871 & 0.210 \\
\hline \multicolumn{5}{|c|}{ Dissimilar material } \\
\hline $5052-\mathrm{Cu}$ & 1980.1 & 2.715 & 0.221 \\
\hline $6061-\mathrm{Cu}$ & 2460.4 & 3.125 & 0.275 \\
\hline
\end{tabular}

This is composition values and Comparison between these materials with a simulation of parameters Stress Vs Strain Curve represented as shown in Figure 6.2 and Stress Vs Deformation as shown figure 6.3. Then FSW material task will ensure in this similar/dissimilar was sustainable being smart consumed in this simulation of this system.

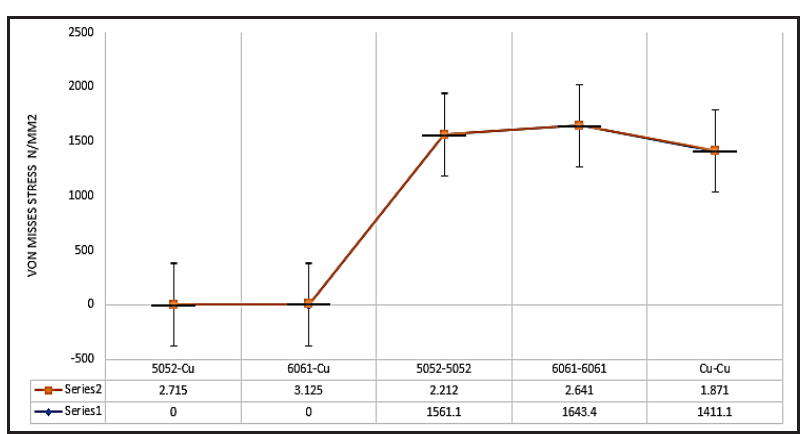

Fig. 7. FSW simulation analysis similar / dissimilar material [Stress Vs Strain curve]

\subsection{Comparison results}

The few combinations of materials of models have been validated before using it is analytic in this validation in uncontained load determined in the design and test data functions. In this special specimen in ANSYS compared to systematically of deformed of this function varies the 
combination of experimental behaviors deeds as comparatively $6 \%$ of works errors as confirmed.

\section{Conclusions}

The finite element simulation model analysed were made in the ANSYS workbench with the consideration of CNC Machine spindle speeds of 1110, 1750 and 2750 RPM. The design is exhibits the standard relations with the combination of alloyed material in FSW to examine it. The various combinations of the $\mathrm{Al}$ 5052, Al 6061 with copper was analysed in the simulation environment in this simulation analysis shows that the $\mathrm{Al} 6061-\mathrm{Cu}$ dissimilar material FSW joint exhibited better strength. In general the comparison of experimental value is differs $1.4 \%$ of error deviation from the simulated results. The aluminum alloy and copper dissimilar joints of FSW exhibited better strength than others. The fabricated FSW lap joint of dissimilar joint of Al 6061 $\mathrm{Cu}$ exhibited better strength at the spindle speed of 1750 RPM, to fabricating of aluminum alloys (Al 6061) and copper $(\mathrm{Cu})$ in $\mathrm{CNC}$ friction stir welding process the spindle speed of 1750 RPM is gives a better tensile strength.

\section{References}

1. Dalong Gao, Ugur Ersoy, Robin Stevenson, PeiChung Wang, J. Manuf. Sci. Eng. 131(6), 061002-12 (2009)

2. Junying Min, Jingjing Li, Yongqiang Li, Blair E. Carlson, Jianping Lin, Wei-MingWang, J. Mater. Process. Tech. 215, 20-29 (2015)

3. S. Lathabai, V. Tyagi, D. Ritchie, T. Kearney, SAE Int. J. Mater. Manuf. 4(1), 589-601 (2011)

4. Junying Min, Jingjing Li, Blair E. Carlson, Yongqiang Li, James F. Quinn, Jianping Lin, Weiming Wang, J. Manuf. Sci. Eng. 137(5), 051022-31 (2015)

5. Zhang, Chang Qing, Xi Jing Wang, Bo Qiang Li, Advanced Materials Research. 183 (2011)

6. Junying Mina, Jingjing Lia, Blair E. Carlsonb, Yongqiang Lib, Jianping Linc, Procedia Engineering. 81, 2036-2041(2014).

7. Rosen, Charles D., Edward Litwinski, and Juan M. Valdez. U.S. Patent No. 6,045,027. 4 Apr. 2000.

8. Derazkola, H. Aghajani, F. Khodabakhshi, A. Simchi, Science and Technology of Welding and Joining. 23(1), 35-49 (2018)

9. Georg J. Schmitz, Ulrich Prahl, Handbook of Software Solutions for ICME. 111-133 (2016)

10. Sara El-Bahloul, Hazem Elshourbagy, Mohammad Al-Makky, Tawfik El-Midany, 15th International Conference On Aerospace Sciences \& Aviation Technology, Cairo, Egypt. (2013)

11. Dezhi Li, Andreas Chrysanthou, Imran Patel, Geraint Williams, Int. J. Adv. Manuf. Technol. 92, 1777-1824 (2017)
12. G. K. Padhy, C. S. Wu, S. Gao, J. Mater. Sci. Technol. 34, 1-38 (2017)

13. W. J. Li, L. F. Yang, Key Engineering Materials. 651, 1439-1444 (2015)

14. Lazarevic, Sladjan, et al. Journal of Manufacturing Science and Engineering. 137(5), 051018 (2015)

15. M. S. M. Sani, N. A. Nazri, D. A. J. Alawi, IOP Conference Series: Materials Science and Engineering. 238 (2017) 